\title{
Older Adults' Affective Experiences Across 100 Days Are Less Variable and Less Complex Than Younger Adults'
}

\author{
Annette Brose \\ KU Leuven and Max Planck Institute for Human Development, \\ Berlin, Germany
}

\author{
Kim de Roover, Eva Ceulemans, and Peter Kuppens \\ KU Leuven
}

\begin{abstract}
Older adults are often described as being more emotionally competent than younger adults, and higher levels of affect complexity are seen as an indicator of this competence. We argue, however, that once age differences in affect variability are taken into account, older adults' everyday affective experiences will be characterized by lower affect complexity when compared with younger adults'. In addition, reduced affect complexity seems more likely from a theoretical point of view. We tested this hypothesis with a study in which younger and older adults reported their momentary affect on 100 days. Affect complexity was examined using clusterwise simultaneous component analysis based on covariance matrices to take into account differences in affect variability. We found that in the majority of older adults $(55 \%)$, structures of affect were comparatively simpler than those of younger adults because they were reduced to a positive affect component. Most remaining older adults (35\%) were characterized by differentiated rather than undifferentiated affective responding, as were a considerable number of younger adults (43\%). When affect variability was made comparable across age groups, affect complexity also became comparable across age groups. It is interesting that individuals with the least complex structures had the highest levels of well-being. We conclude that affective experiences are not only less variable in the majority of older adults, but also less complex. Implications for understanding emotions across the life span are discussed.
\end{abstract}

Keywords: emotional complexity, positive and negative affect, emotional aging, emotion differentiation, clusterwise simultaneous component analysis

Research on emotional aging suggests that with older age comes more emotional competence. One of the pieces of evidence for this proposition comes from research on affect complexity in daily life, where findings of increased complexity with age are seen as supporting the notion that older adults have greater competencies in the emotional domain (Carstensen, Pasupathi, Mayr, \& Nessel-

This article was published Online First January 19, 2015.

Annette Brose, Institute of Psychology, KU Leuven; Center for Lifespan Psychology, Max Planck Institute for Human Development, Berlin, Germany. Kim de Roover, Eva Ceulemans, and Peter Kuppens, Institute of Psychology, KU Leuven.

Annette Brose is now at the Humboldt University Berlin.

The COGITO study was supported by the Max Planck Society, including a grant from the Max Planck Society's innovation fund (M.FE.A.BILD0005), the Alexander von Humboldt Foundation's Sofja Kovalevskaja Award (to Martin Lövdén) donated by the German Federal Ministry for Education and Research (BMBF), the German Research Foundation (DFG; KFG 163), and the BMBF (CAI). Furthermore, the research leading to the results reported in this article was supported in part by the Interuniversity Attraction Poles program financed by the Belgian government (IAP/P7/06) and by the Research Fund of KU Leuven (GOA/ 15/003). We thank Florian Schmiedek, Ulman Lindenberger, and Martin Lövdén for their invaluable contributions to the COGITO study.

Correspondence concerning this article should be addressed to Annette Brose, Humboldt University Berlin, Institute of Psychology, Unter den Linden 6, 10099 Berlin, Germany. E-mail: annette.brose@hu-berlin.de roade, 2000; Carstensen et al., 2011). However, empirical findings on this issue are not conclusive, with some pointing to more and others to less or no differences in structural complexity in daily life (for a review, see Grühn, Lumley, Diehl, \& Labouvie-Vief, 2013).

Here, we first question whether it is indeed theoretically plausible to predict an age-related increase in emotional complexity in everyday life. Second, we question the empirical basis of higher affect complexity in older age because the findings in support of this notion typically do not take into account the decreased levels of affect variability in older adults (Röcke \& Brose, 2013; Röcke, $\mathrm{Li}$, \& Smith, 2009). We argue that because current measures of affect complexity are confounded with affect variability, a consideration of age differences in affect variability will affect findings regarding age differences in affect complexity. Our approach should reveal reduced rather than increased affect complexity in older adulthood in daily life.

\section{Age Group Differences in Structural Complexity of Affective Experiences}

The term "affect complexity" refers to two different aspects of emotional experiences: (a) the co-occurrence of pleasant and unpleasant affective states in the same moment (i.e., ambivalent states including positive affect [PA] and negative affect [NA]), and (b) a differentiated pattern of emotional responding (i.e., a nuanced, situation-specific understanding and processing of emotional episodes). These definitions are in line with central publications on affect complexity (Lindquist \& Barrett, 2008) and 
emotional aging (e.g., Carstensen et al., 2000; for review, see Grühn et al., 2013).

The literature on adult age differences in affect complexity in daily life has been recently reviewed (Grühn et al., 2013; Hay \& Diehl, 2011; Riediger \& Rauers, 2014). Table 1 provides an overview of the studies reviewed. On the empirical side, five studies targeted or touched on the development of affect complexity in daily life (Carstensen et al., 2000, 2011; Hay \& Diehl, 2011; Ong \& Bergeman, 2004; Riediger, Schmiedek, Wagner, \& Lindenberger, 2009; Scott, Sliwinski, Mogle, \& Almeida, 2014). Two additional studies took a critical perspective on this topic by clarifying operationalizations and providing results for a multitude of indicators of affect complexity (Grühn et al., 2013; Ready, Carvalho, \& Weinberger, 2008). Despite these efforts to resolve the issue of age differences in affect complexity, the findings are inconclusive, with some pointing to more or less complexity with increasing age, and others reporting no age differences. Here, we offer a new view on affect complexity in adulthood. We argue that older age should be characterized by reduced, not increased, affect complexity in daily life, and we will explain this argument in the following sections.

\section{Theoretical Considerations in the Development of Affect Complexity}

The first reason for questioning the proposition that affect complexity increases with age is its incompatibility with important other aspects of emotional aging. One theoretical framework that shapes the current thinking on affect complexity and age is socioemotional selectivity theory (SST). According to SST, older adults' increased awareness that time left to live is limited results in the motivation to engage in emotionally meaningful goals. This comes with the "intensified desire for and ultimate experience of more positive and less negative emotions over time" (ErsnerHershfield, Mikels, Sullivan, \& Carstensen, 2008, p. 159), but also with more complex emotional experiences (Carstensen et al., 2000). Regarding the latter, SST argues that older adults try to find meaning in social relationships, even conflictual ones, and that they savor emotional moments, including negative ones. According to SST, greater investment in meaningful activities under time-limited conditions should elicit more complex emotional experiences among older adults.

This proposition can be critiqued on a number of grounds, especially when thinking about affective experiences in daily life. First, regarding social relationships in different age groups, older adults engage in more gratifying social relationships (Luong, Charles, \& Fingerman, 2011). They select emotionally rewarding social contacts over others, which should go hand in hand with the experience of more positive, but not more mixed, emotions. Second, daily life seems to be more pleasant during old age because the exposure to daily stressors is reduced (Brose, Scheibe, \& Schmiedek, 2013). This is associated with lower levels of experienced NA and, in turn, should limit the experience of mixed emotions. Third, older adults show preferences for routines and sedentary activities, a finding that also calls into question whether their daily lives are indeed characterized by more meaningful activities than younger adults' on a day-to-day basis (Bouisson \& Swendsen, 2003; Rosenkoetter, Garris, \& Engdahl, 2001). Thus, the notion of increased emotional complexity in old age as emerg-

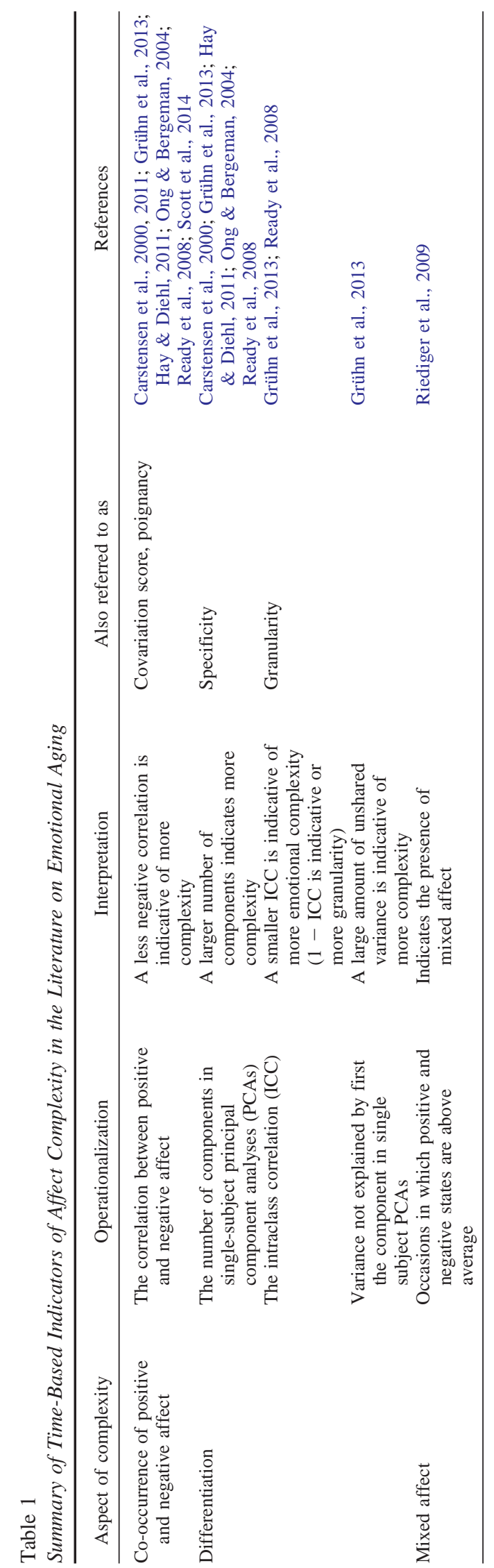


ing from meaningful and yet emotionally ambivalent situations (Carstensen et al., 2000) does not seem to be applicable in the context of many everyday activities. Instead, these three points speak for lowered occurrence and less variability of NA and, therefore, less complexity. To be clear, in this study we do not question SST as a whole, and we do not have doubts that older adults experience mixed emotions in meaningful moments. Rather, we argue that mixed emotions should be reduced in older adults' everyday experiences rather than increased.

Given the arguments raised previously, instead of more affect complexity during such everyday experiences, we argue that reduced complexity in older adulthood is likely. Such a view is more compatible with dynamic integration theory (DIT; Labouvie-Vief, 2003). According to DIT, emotional complexity arises from the integration of current emotional experiences with past moments and the emotions experienced by others. That is, affect complexity is a consequence of the organization of affect across time and contexts. As such, organization requires cognitive capacities (e.g., reflection, monitoring) and prior exposure. This means that peak levels of complexity should occur in middle adulthood, and that emotional complexity should be constrained in older adulthood. Moreover, older adults may actively avoid complex emotional experiences to conserve cognitive resources (Labouvie-Vief, Grühn, \& Studer, 2010). Together, we argue that these theoretical arguments speak for reduced complexity in older adults.

\section{Empirical Approaches to Age Differences in Affect Complexity}

Our second reason for questioning the notion of age-related increases in affect complexity lies in its empirical basis. This basis mainly comes from studies that used experience sampling or diary methods and tested affective experiences within individuals across time. The resulting time series data allow the estimation of socalled time-based indicators of emotional complexity (Grühn et al., 2013; for an overview, see Table 1). These indicators are called time-based because they are based on covariation patters of different facets of affect (e.g., anger, fear) across time. We argue that two of these indicators of complexity, the co-occurrence and differentiation indices, share a more fundamental problem, namely that both are influenced by the amount of affect variability within individuals. It is important that a critical age difference in withinperson affective experiences in daily life is reduced variability with increasing age (Riediger \& Rauers, 2014; Röcke \& Brose, 2013). For example, Grühn et al. (2013) reported a decrease in the within-person $S D$ across adulthood (see also Brose et al., 2013; Röcke et al., 2009; Steptoe, Leigh, \& Kumari, 2011). One reason for this age difference seems to be a decrease in the occurrence of NA (i.e., floor effects). We now elaborate on the effects of variability on the co-occurrence and differentiation indices and explain why conclusions based on these indices may be misleading.

\section{The Co-Occurrence Index}

The co-occurrence index is commonly operationalized as the within-person correlation between aggregates of positive and negative states across time. A within-person correlation that is closer to zero (i.e., less negative) is interpreted as indicative of more co-occurrence of positive and negative affective states (Carstensen et al., 2000). This may be a misinterpretation, however. Weaker correlations can be because of restriction of range: If PA and NA levels hardly vary across time, their respective within-person $S D$ s are small and as a consequence, the correlation between PA and NA is closer to zero (i.e., the variances of PA and NA determine the size of the correlation coefficients). It follows that an agerelated reduction of the negative association between PA and NA may emerge from reduced variability - whether this is the case cannot be resolved when merely providing information about the co-occurrence index. This issue has been highlighted previously (Grühn et al., 2013), and one very recent publication empirically addressed it (Scott et al., 2014), but with a different emphasis than this study.

\section{The Differentiation Index}

The differentiation index is commonly operationalized as the number of components in single-subject principal component analysis (PCA; Eigenvalue $>1$ criterion) where the PCAs are based on correlation matrices. A high number of components reflects the independent experience of different facets of emotions across time (i.e., the nuanced, occasion-specific experience of, for example, anger and nervousness). ${ }^{1}$ There is, however, a problem with this index at the computation level, because the use of correlation matrices does not take differences in the items' variances into account. Differences in variance may occur between individuals (e.g., younger vs. older adults) and within individuals across items (e.g., nervousness may vary more than fear). Irrespective of these likely differences, all items' variances are by definition calculated to be one in the analysis of correlation matrices. As a consequence, a relatively large number of components may occur if, for example, rare negative emotions occur at different time points. Merely counting the number of components will disguise the relative relevance of specific affective states. To illustrate, an individual who experiences frequent ups and downs of multiple positive emotions, but almost no fluctuations in negative emotions (which will all be set to have equal variances), can have the same level of affect complexity as an individual who experiences frequent ups and downs in both the positive and negative domain. Yet, arguably, the first individual's emotional experiences should be considered less complex because of the absence of variability in the negative domain. In more general terms, this method implies that observed variables with hardly any variability may become relevant indicators of a component of affective experience. We believe, however, that variability is the essence of time-based indi-

\footnotetext{
${ }^{1}$ Unfortunately, the differentiation index has been misinterpreted in the past. A high number of components has incorrectly been described as being indicative of more mixed emotional experiences or a blend of emotions within the same moment (Charles, 2005; Magai, Consedine, Krivoshekova, Kudadjie-Gyamfi, \& McPherson, 2006). Such confusion may stem from an imprecise mapping of the term "complexity" to its operationalization in the first place. For example, Carstensen et al. (2000, p. 645) hypothesized that "emotional experience is more complex in older as compared with younger adults. Because the pursuit of emotionally meaningful goals often entails mixed emotions, we anticipate a more complex dimensional structure to the emotional experience of older adults." In this hypothesis, a more complex dimensional structure in older adults (i.e., a structure with more components) is expected because older adults are assumed to experience more mixed emotions. However, mixed emotions should be reflected by a lower-dimensional structure.
} 
cators of emotional complexity, because it indicates the presence of emotional responding to begin with.

Given these issues, we question the use of the co-occurrence and differentiation indices for the representation of age differences in affect complexity. We argue that analyses of affect complexity should be based on covariance and not on correlation matrices. We do not claim that the analysis of correlation matrices is wrong, but that because differences in variability are reflected in the solutions, the analysis of covariance matrices yields a more appropriate representation of age differences in structural complexity. We hypothesize that taking into account the reduced affect variability displayed by older adults should result in reduced complexity in this age group. In the next section, we introduce a methodological approach to test this hypothesis.

\section{Clusterwise Simultaneous Component Analysis: A Method to Approach Age Differences in Affect Complexity}

The major analytical approach of this study is clusterwise simultaneous component analysis (clusterwise SCA-P; P stands for invariant patterns), a component analysis method developed to identify clusters of data blocks that share structural characteristics (De Roover, Ceulemans, \& Timmerman, 2012; De Roover, Ceulemans, Timmerman, \& Onghena, 2013). The method is well suited to investigate whether the emerging clusters differ on specific covariates (e.g., traits). In this study, we will use clusterwise SCA-P to analyze the repeated observations of affect from multiple individuals simultaneously. In single-subject component analysis, the number of components and the loading matrices reflect the structures of within-person variability across time. That is, the solutions reflect how the different items covary across time in a single individual. The goal of clusterwise SCA-P is instead to identify clusters of individuals that are distinguishable in terms of the structural characteristics of their affective experiences. We expect age differences to become apparent in age-group specific cluster membership. Similar to previous research, we will inspect the co-occurrence of PA and NA, as well as affect differentiation.

Crucially, in this study clusterwise SCA-P is based on covariance matrices when analyzing structural complexity. Therefore, age differences in variability should be adequately taken into account in the cluster solutions, because people who hardly vary on (some of the) items will be assigned to a cluster that shows a loading pattern in which these items have almost zero loadings on respective components, implying that less components may be needed to adequately describe the data. People who do vary on all the items will belong to clusters in which all items have at least one clear nonzero loading.

Over and above this crucial feature, we think that clusterwise SCA-P has important benefits in the context of investigating systematic age differences. First, we are primarily interested in age group differences in the structural aspects of affect variability, with the aim of generalizing across individuals of one age group, and less interested in each individual's structural characteristics. This speaks for a clustering method, which yields output for groups of individuals. Second, we assume that younger and older adults do not belong to the same population in terms of affect structures. An exploratory search for clusters in clusterwise SCA-P should thus group individuals of the two age groups in different clusters, and we expect that the clusters will differ in terms of complexity. Clusters with mainly older adults should be less complex than clusters with mainly younger adults. Together, the use of clusterwise SCA-P allows us to formulate more nomothetic conclusions about structural similarities and differences within and between clusters.

\section{The Present Study}

This study investigates adult age differences in affect complexity while taking into account differences in affect variability. We do this in four steps. First, we analyze affect complexity in accordance with previous studies' approaches (i.e., the co-occurrence and differentiation indices). In doing so, we establish links to previous findings in the literature, but given the heterogeneous pattern of previous findings, we do not have clear expectations regarding age differences. Second, we examine affect complexity by modeling covariance rather than correlation matrices using clusterwise SCA-P. We hypothesize that this approach will reveal reduced complexity in older compared with younger adults (less co-occurrence of PA and NA, less differentiation), because this approach will take into account the low affect variability typical of older adults. In this context, we will also demonstrate why we think that previously used indicators resulted in misleading conclusions regarding age group differences. Third, to explore age differences in affect structures if there were no age differences in variability, we repeat the clusterwise SCA-P analyses with a subsample of younger and older adults that are matched on affect variability. In addition, this step will further demonstrate the strong effect of variability on complexity. Fourth, we establish relationships between complexity and indicators of well-being. Affect complexity has previously been discussed as an important correlate of potentially improved emotional competencies and wellbeing (Carstensen et al., 2000; Ong \& Bergeman, 2004). The underlying rationale is that it reflects the ability to discriminate between different emotions, and hence also a better understanding of situations and adequate behavioral and regulatory responses (Barrett, Gross, Christensen, \& Benvenuto, 2001; Lindquist \& Barrett, 2008). We explore whether this association also holds in this study. We predict that older adults have lower levels of affect complexity, but we also know from previous work that older adults have higher levels of well-being. We examine whether high levels of emotional stability and reduced complexity is an additional route to high levels of well-being.

\section{Method}

This study is part of a larger study, the COGITO study, conducted at the Center for Lifespan Psychology, Max Planck Institute for Human Development, Berlin (Schmiedek, Lövdén, \& Lindenberger, 2009). The COGITO study follows a pretest-posttest control group design, with a microlongitudinal study phase of about 100 days in the experimental group. The present study reports data from this phase.

\section{Participants and Procedures}

This study included 101 younger adults $(51.5 \%$ women; age $=$ 20-31 years, $M=25.6, S D=2.7)$ and 103 older adults $(49.5 \%$ 
women; age $=65-80$ years, $M=71.3, S D=4.1)$. The younger and older adults had on average 12.5 and 10.8 years of high school education respectively, and both age groups had representative levels of general cognitive function (Schmiedek, Lövdén, \& Lindenberger, 2009). They reported better subjective health but no difference in the number of doctor visits than a representative German sample (Wolff et al., 2013). Study participation began and ended in group sessions with 10 days of pre- and posttests (2-2.5 hr). The microlongitudinal phase (87 to 107 sessions, $M=101$ sessions, 1-1.5 hr each) was scheduled on an individual basis. During this phase, participants worked on computerized tasks individually in rooms with 3 to 6 computers. These sessions were carried out from Monday to Saturday between 8 a.m. and 7:30 p.m. The participants first worked on self-reports (5-8 min), followed by 12 different cognitive tasks (40-65 min). The sessions concluded with self-report (1-2 min). For details on procedures, see Schmiedek et al. (2009).

\section{Measures}

Daily affect. PA and NA was assessed with a German version of the Positive and Negative Affect Schedule (PANAS; Watson, Clark, \& Tellegen, 1988). Individuals were asked to rate how well the PANAS adjectives described their momentary mood on an 8-point scale ranging from 0 (does not apply at all) to 7 (applies very well). The PANAS was the first questionnaire in each daily session. $^{2}$ This position was chosen to minimize the effects of the testing session on affective experiences. Items were presented in random order across days.

Indicators of well-being. This study examined four aspects of well-being. Depressive symptoms were measured with a German version of the Center for Epidemiological Studies Depression Scale (CES-D; Hautzinger, 1988; Cronbach's alpha $=.86$ ). Trait PA and NA were tested using a trait version of the PANAS in which participants rated the frequency of the 20 PANAS items across the last year. Cronbach's alpha for the PA and NA subscale were .86 and .91 , respectively. In addition to the PANAS, this study examined individual differences on the valence dimension of the affect circumplex, using two positive and two negative items (sad, discontent, cheerful, and happy). The scale will be referred to as "happiness" in the following sections. Cronbach's alpha of the scale was .66.

\section{Statistical Analyses}

Step 1. Conventional analysis of structural complexity in the different age groups. We first investigated age group differences in affect complexity with the methods commonly used in previous research. That is, we determined per individual the cooccurrence of PA and NA (i.e., the correlation of PA and NA across study time) and the differentiation index (i.e., the number of independent components using single subject PCAs and the Eigenvalue $>1$ criterion).

Step 2a. Clusterwise SCA-P. We then investigated age differences in the underlying structure of affective experiences using our new approach, clusterwise SCA-P (De Roover et al., 2013) based on covariance matrices. De Roover et al. (2012) provide a step-by-step overview of how to run a clusterwise SCA analysis, and the analyses are implemented in Matlab scripts, which are available upon request. In clusterwise SCA-P, the data of single subjects are assigned to mutually exclusive groups and are then modeled with simultaneous component analysis (i.e., a PCA that is performed on the concatenated, person-mean centered data of multiple individuals). To assign individuals to clusters, the scores that are expected given the component structure in the different clusters are computed. Each individual is then assigned to the cluster for which he or she has the smallest difference between these expected scores and the scores that are actually observed. The loading patterns of the emerging, mutually exclusive clusters are invariant across the subjects belonging to the same clusters. Individuals' time series belonging to the same cluster can thus be reconstructed by means of the same loadings. In SCA-P, component variances and covariances are allowed to vary across subjects within each cluster.

Clusterwise SCA-P starts with selecting the number of clusters, $C$, and components, $Q$ (De Roover et al., 2012; De Roover et al., 2013). This is achieved by (a) estimating solutions using different values for $C$ and $Q$, (b) determining the percentage of varianceaccounted-for (VAF) of the different solutions, and (c) computing scree ratios with VAFs stemming from different values of $C$ and $Q$. The $C$ value with the highest scree ratio across different $Q$ values is retained first. Second, scree ratios with varying $Q$ values are calculated; for $Q$, the number with the highest scree ratio is retained. To fit a clusterwise SCA-P solution with $C$ clusters and $Q$ components to a data matrix, an alternating least squares (ALS) algorithm is used (for details, see de Roover et al., 2013). It finds the matrix of subjects' cluster belongings, the component score matrices of the different clusters, and the clusters' loading matrices.

Further procedural details are as follows. The raw data were first corrected for a linear trend across study time and then centered per subject (i.e., for each person, the item-specific means were subtracted from the trend-corrected raw values). Cluster-specific SCA-P models were obliquely rotated for the ease of interpretation.

Step 2b. Clusterwise SCA-P, comparison with results from conventional procedures. Findings from conventional analyses were then mapped onto the solutions from clusterwise SCA-P, separately for the different age groups, and together with information on age differences in variability. This analysis demonstrates how the different approaches lead to different conclusions and indicates that conclusions regarding affect complexity are related to whether affect variability is taken into consideration.

Step 3. Clusterwise SCA-P with younger and older adults matched on variability. Next, clusterwise SCA-P was repeated with subsamples of younger and older adults matched on affect variability. The purpose of this third step was to explore age differences in affect structures if there were no differences in variability. We matched younger and older adults using propensity score matching (Ho, Imai, King, \& Stuart, 2007). First, individuals' propensity to belong to one or the other age group was estimated by means of

\footnotetext{
2 The average internal consistency of the NA items across Sessions 1 to 100 was $.80(S D=.05)$ in the younger subsample, and it was $.67(S D=$ .12) in the older subsample. The average internal consistency of the PA items across Sessions 1 to 100 was $.83(S D=.03)$ in the younger subsample, and it was .78 $(S D=.06)$ in the older subsample. Note that PA and NA items were not aggregated to subscales in this study.
} 
logistic regression (outcome variable: the binary variable "age group"). Predictors were the within-person SDs of all 20 affect items across study time. The predicted values are the propensity scores. Second, a one-to-one matching procedure was used to identify pairs of younger and older adults with similar propensity scores, and thus, levels of affect variability. The resulting subsamples $(N=54)$ did not differ on any of the 20 affect items in terms of variability. Their data were subjected to a similar clusterwise SCA-P as previously mentioned.

Step 4. Affect complexity and well-being. Relationships between affect complexity and indicators of well-being were established with analyses of variance (ANOVA). In particular, we investigated the levels of well-being in the different clusters that emerged from clusterwise SCA-P and that clearly differed in structural complexity.

\section{Results}

\section{Descriptive Statistics}

Table 2 provides information on the within-person means, SDs, covariances and correlations among the raw NA items, separately for the two age groups. Table 3 provides the same information for the PA items. The general pattern of age differences reveals lower NA and higher PA levels in older compared with younger adults, as well as lower variability in older adults on the majority of items. The correlations among multiple items could not be estimated in some younger and a relatively greater number of older adults as a consequence of the absence of variability on items across time.

Aim 1. Conventional analysis of structural complexity in the different age groups. We first computed the co-occurrence and differentiation indices. These analyses revealed an average PA-NA correlation of $-.16(S D=.24)$ in younger adults and of $-.14(S D=$ $.26)$ in older adults. The difference was not significant, $F(1,199)=$ $0.29, p=.59$. Second, we computed the number of components in PCAs (Eigenvalue $>1$ criterion). The means for younger and older adults were $5.49(S D=1.23$; range $=3$ to 8$)$ and $5.77(S D=1.37$; range $=2$ to 9$)$, respectively. The difference was not significant, $F(1$, $203)=2.38, p=.12$. In sum, we did not find age differences in affect complexity on the co-occurrence and differentiation indices.

Aim 2a. Approaching affect complexity with clusterwise SCA-P. Next, we examined affect complexity with clusterwise SCA-P based on covariance matrices. Decisions about the number of clusters and components were based on incremental percentages of variances that were explained by the different solutions (scree ratios of the percentages of VAF). The respective scree plots of the percentages of VAFs for the different numbers of clusters and components are visualized in Figure 1A. Three clusters of individuals that differed in structural characteristics emerged. According to the scree ratios in Figure 1A, allowing for more than three clusters does not yield a substantial gain in variance explained-the line of the four-cluster solution lies only slightly above the line of the three-cluster solution. In addition, the "elbow" of the scree lines occurred at two components (i.e., the incremental amount of variance explained drops after the two-component solution). This led to our decision to keep three clusters with two components.

An initial inspection of the loading matrices of three clusters revealed that one cluster had two components that reflect PA experiences (i.e., loadings of the NA items were close to zero). Therefore, using another scree test, we tested whether a one-component solution came with a significant loss in information in comparison to the two-component solution. Figure 1B represents this follow-up analysis. In particular, we inspected the VAFs of a one- and twocomponent solution for this cluster, which we refer to as the PA-

Table 2

Descriptive Statistics Negative Affect: Intraindividual Means and SDs, and Correlations

\begin{tabular}{|c|c|c|c|c|c|c|c|c|c|c|c|c|c|}
\hline & $M$ & $S D(M)$ & $S D$ & $S D(S D)$ & 2 & 3 & 4 & 5 & 6 & 7 & 8 & 9 & 10 \\
\hline \multicolumn{14}{|l|}{ Younger } \\
\hline (1) Distressed & 1.45 & 1.06 & 1.15 & 0.46 & 0.42 & 0.34 & 0.31 & 0.29 & 0.35 & 0.32 & 0.27 & 0.28 & 0.34 \\
\hline (2) Upset & 1.03 & 0.90 & 1.08 & 0.45 & & 0.29 & 0.28 & 0.49 & 0.50 & 0.30 & 0.25 & 0.27 & 0.27 \\
\hline (3) Guilty & 0.72 & 0.90 & 0.71 & 0.44 & & & 0.31 & 0.23 & 0.24 & 0.44 & 0.24 & 0.20 & 0.31 \\
\hline (4) Scared & 0.59 & 0.77 & 0.60 & 0.45 & & & & 0.23 & 0.25 & 0.33 & 0.33 & 0.30 & 0.53 \\
\hline (5) Hostile & 0.76 & 0.89 & 0.71 & 0.47 & & & & & 0.49 & 0.21 & 0.19 & 0.20 & 0.22 \\
\hline (6) Irritable & 1.27 & 1.04 & 0.97 & 0.43 & & & & & & 0.24 & 0.27 & 0.31 & 0.22 \\
\hline (7) Ashamed & 0.71 & 0.95 & 0.66 & 0.45 & & & & & & & 0.26 & 0.22 & 0.31 \\
\hline (8) Nervous & 1.25 & 1.00 & 0.94 & 0.42 & & & & & & & & 0.53 & 0.34 \\
\hline (9) Jittery & 1.59 & 1.14 & 1.01 & 0.42 & & & & & & & & & 0.32 \\
\hline (10) Afraid & 0.66 & 0.84 & 0.65 & 0.43 & & & & & & & & & \\
\hline \multicolumn{14}{|l|}{ Older } \\
\hline (1) Distressed & 0.34 & 0.59 & 0.50 & 0.46 & 0.27 & 0.25 & 0.31 & 0.23 & 0.28 & 0.26 & 0.26 & 0.29 & 0.30 \\
\hline (2) Upset & 0.25 & 0.51 & 0.41 & 0.43 & & 0.22 & 0.23 & 0.33 & 0.33 & 0.28 & 0.22 & 0.21 & 0.20 \\
\hline (3) Guilty & 0.11 & 0.33 & 0.21 & 0.28 & & & 0.23 & 0.17 & 0.17 & 0.35 & 0.15 & 0.16 & 0.28 \\
\hline (4) Scared & 0.13 & 0.37 & 0.20 & 0.32 & & & & 0.17 & 0.24 & 0.29 & 0.29 & 0.28 & 0.50 \\
\hline (5) Hostile & 0.14 & 0.53 & 0.18 & 0.29 & & & & & 0.24 & 0.23 & 0.19 & 0.17 & 0.17 \\
\hline (6) Irritable & 0.50 & 0.88 & 0.45 & 0.44 & & & & & & 0.19 & 0.34 & 0.28 & 0.20 \\
\hline (7) Ashamed & 0.13 & 0.35 & 0.22 & 0.28 & & & & & & & 0.16 & 0.18 & 0.31 \\
\hline (8) Nervous & 0.69 & 1.11 & 0.48 & 0.37 & & & & & & & & 0.48 & 0.32 \\
\hline (9) Jittery & 0.70 & 1.12 & 0.50 & 0.39 & & & & & & & & & 0.32 \\
\hline (10) Afraid & 0.15 & 0.40 & 0.20 & 0.31 & & & & & & & & & \\
\hline
\end{tabular}

Note. $S D(M)$ and $S D(S D)$ refer to the standard deviations of the intraindividuals means and SDs. Correlations could not be estimated in all individuals: In younger adults, $10 \%$ of the pairwise correlations could not be estimated; in older adults, 53\% of the pairwise correlations could not be estimated. 
Table 3

Descriptive Statistics Positive Affect: Intraindividual Means and SDs, and Correlations

\begin{tabular}{|c|c|c|c|c|c|c|c|c|c|c|c|c|c|}
\hline & $M$ & $S D(M)$ & $S D$ & $S D(S D)$ & 2 & 3 & 4 & 5 & 6 & 7 & 8 & 9 & 10 \\
\hline \multicolumn{14}{|l|}{ Younger } \\
\hline (1) Enthusiastic & 2.39 & 1.24 & 1.08 & 0.37 & 0.42 & 0.38 & 0.41 & 0.33 & 0.30 & 0.38 & 0.35 & 0.34 & 0.37 \\
\hline (2) Excited & 2.96 & 1.33 & 1.05 & 0.35 & & 0.33 & 0.43 & 0.27 & 0.29 & 0.36 & 0.37 & 0.34 & 0.35 \\
\hline (3) Strong & 3.33 & 1.34 & 0.92 & 0.32 & & & 0.38 & 0.41 & 0.38 & 0.33 & 0.40 & 0.39 & 0.45 \\
\hline (4) Interested & 3.21 & 1.25 & 0.91 & 0.31 & & & & 0.25 & 0.36 & 0.37 & 0.37 & 0.45 & 0.43 \\
\hline (5) Proud & 2.58 & 1.52 & 0.99 & 0.45 & & & & & 0.25 & 0.27 & 0.31 & 0.25 & 0.31 \\
\hline (6) Alert & 3.63 & 0.96 & 1.01 & 0.30 & & & & & & 0.29 & 0.32 & 0.46 & 0.49 \\
\hline (7) Inspired & 2.42 & 1.24 & 1.04 & 0.36 & & & & & & & 0.32 & 0.35 & 0.36 \\
\hline (8) Determined & 3.39 & 1.27 & 1.02 & 0.34 & & & & & & & & 0.37 & 0.39 \\
\hline (9) Attentive & 3.47 & 1.01 & 0.91 & 0.28 & & & & & & & & & 0.44 \\
\hline (10) Active & 3.50 & 1.15 & 0.96 & 0.30 & & & & & & & & & \\
\hline \multicolumn{14}{|l|}{ Older } \\
\hline (1) Enthusiastic & 4.30 & 1.73 & 0.63 & 0.31 & 0.34 & 0.26 & 0.29 & 0.20 & 0.27 & 0.29 & 0.30 & 0.29 & 0.31 \\
\hline (2) Excited & 4.76 & 1.58 & 0.64 & 0.32 & & 0.26 & 0.37 & 0.18 & 0.29 & 0.32 & 0.33 & 0.35 & 0.32 \\
\hline (3) Strong & 4.16 & 1.61 & 0.68 & 0.30 & & & 0.25 & 0.23 & 0.34 & 0.26 & 0.28 & 0.30 & 0.35 \\
\hline (4) Interested & 5.31 & 1.28 & 0.54 & 0.28 & & & & 0.13 & 0.29 & 0.29 & 0.32 & 0.39 & 0.34 \\
\hline (5) Proud & 2.62 & 2.07 & 0.54 & 0.37 & & & & & 0.15 & 0.16 & 0.16 & 0.18 & 0.18 \\
\hline (6) Alert & 4.79 & 1.19 & 0.63 & 0.28 & & & & & & 0.31 & 0.31 & 0.39 & 0.39 \\
\hline (7) Inspired & 4.56 & 1.43 & 0.77 & 0.33 & & & & & & & 0.29 & 0.33 & 0.34 \\
\hline (8) Determined & 4.98 & 1.37 & 0.67 & 0.31 & & & & & & & & 0.37 & 0.34 \\
\hline (9) Attentive & 5.14 & 1.20 & 0.56 & 0.27 & & & & & & & & & 0.39 \\
\hline (10) Active & 4.88 & 1.31 & 0.60 & 0.29 & & & & & & & & & \\
\hline
\end{tabular}

Note. $S D(M)$ and $S D(S D)$ refer to the standard deviations of the intraindividuals means and SDs. Correlations could not be estimated in all individuals: in younger adults, $0.5 \%$ of the pairwise correlations could not be estimated; in older adults, $4 \%$ of the pairwise correlations could not be estimated.

Cluster. According to the "elbow" of the respective line, the loss of fit in dropping the second cluster was not too high, suggesting that retaining one component was sufficient for this cluster. In other words, the PA-Cluster could be described well with a one-component solution. A similar scree plot was drawn for the remaining clusters (Figure 1B), which we call the PA-Differentiated-NA-Cluster and PA-NA-Cluster. Here, the two-component solutions fitted better than the one-component solution. Therefore, both components were retained in those clusters.

The clusters that emerged from the use of SCA-P will now be described in more detail. The loading patterns of the three clusters are presented in Table 4. These solutions were obliquely rotated (i.e., with Harris-Kaiser independent cluster rotation; Kiers \& Tenberge, 1994). By any standard, the one-component structure of the PA-Cluster, with only positive items loading one component, can be considered as the least complex structure. The structure of the PA-Differentiated-NACluster is two-dimensional, but the loadings of the NA component are more heterogeneous in size than those of the NA component in the PA-NA-Cluster. That is, individuals belonging to this cluster have affective experiences in daily life that are reduced in scope (i.e., only few items have high loadings on the NA component). At the same time, affect is more differentiated here than in individuals belonging to the PA-NA-Cluster. The PA-NA-Cluster also has two components, but the NA component has a broader scope as all NA items have relatively high loadings. The PA-NA-Cluster could thus be referred to as more complex than Cluster 1 because positive and negative experiences play a role in daily life. In comparison to the PA-Differentiated-NA-Cluster, however, the PA-NA-Cluster seems less complex because all NA states covary simultaneously, reflecting a less differentiated response pattern. Differences in complexity between the PA-NA-Cluster and the PA-Differentiated-NA-Cluster thus emerged in the loading patterns, not in the number of compo- nents. In both the PA-Differentiated-NA and PA-NA-Cluster, the component intercorrelations are small and negative.

As expected, participants in the different age groups were not equally distributed across the clusters (Table 5), $x^{2}=45.65$, $p<.0001$. The majority of older adults belong to the PACluster, a minority belongs to the PA-Differentiated-NACluster, and only a few belong to the PA-NA-Cluster. The younger adults mainly belong to the PA-Differentiated-NAand the PA-NA-Cluster. Drawing on the preceding cluster descriptions, the majority of older adults can be characterized as being the least affectively complex. Most remaining older adults belong to the PA-Differentiated-NA-Cluster, suggesting that they have a relatively differentiated structure with regard to NA experiences.

Table 4 also presents the cluster-specific variability for each item. As expected, the three clusters vary in item-specific variances. The PA-Cluster has particularly small SDs on all NA items, the PA-Differentiated-NA-Cluster has small SDs on some NA items, and the PA-NA-Cluster has comparable SDs across all NA items. This illustrates that differences in variability affect the loading patterns. Items with low variances contribute less to the components.

In addition, we investigated age differences in the cooccurrence of PA and NA within the PA-Differentiated-NA and the PA-NA Cluster (Table 5). Age group differences in component correlations were not significant, $F(1,78)=0, p=.97$, and $F(1,52)=.14, p=.71$, respectively. Thus, aside from the majority of older adults without a NA component, there are no signs of more or less co-occurrence of PA and NA.

Aim 2b. Clusterwise SCA-P, comparison with results from conventional procedures. In the following, we map the results from conventional approaches to affect complexity onto the 

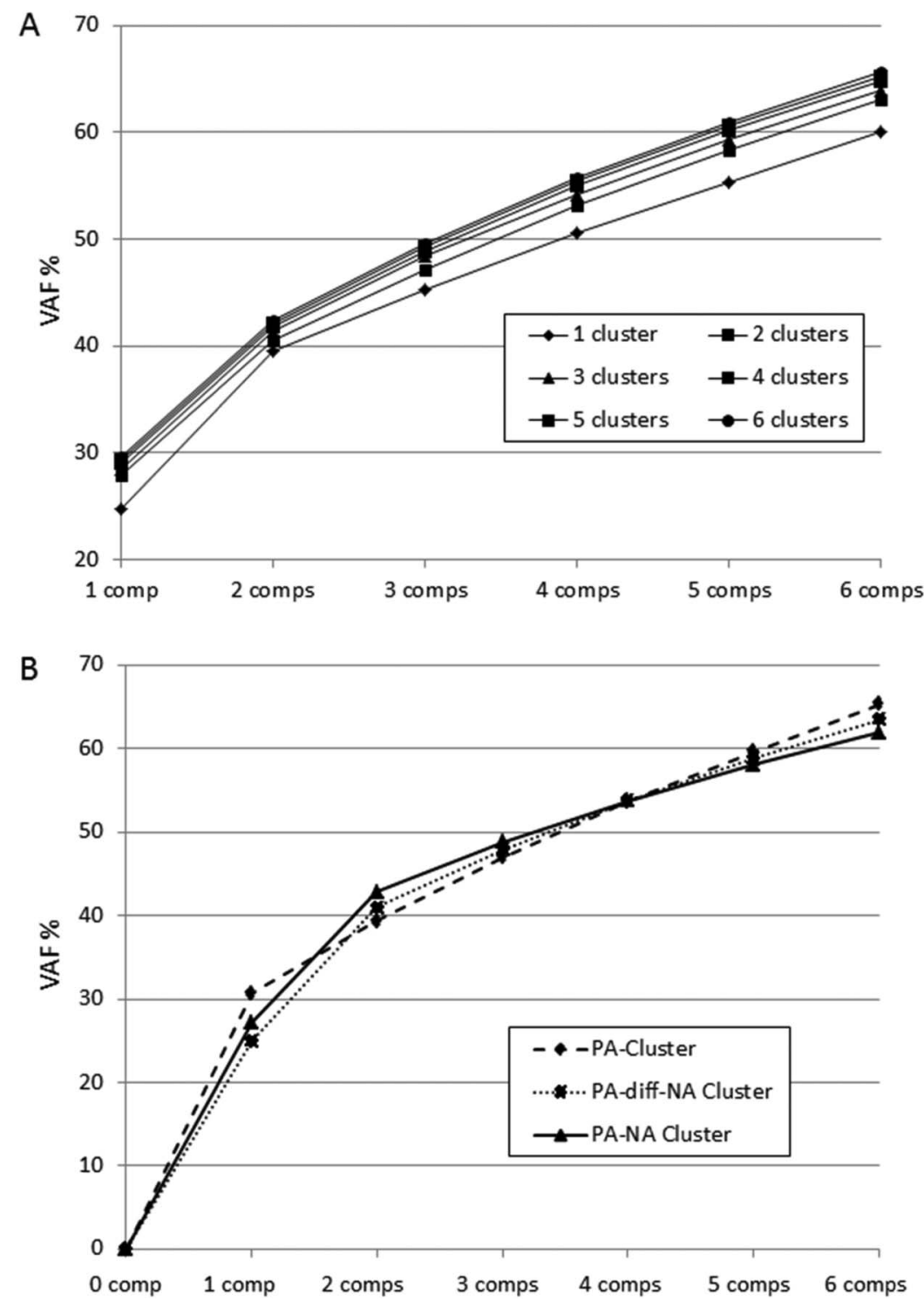

Figure 1. (A) Percentages of variance-accounted-for (VAF) of clusterwise simultaneous component analysis (clusterwise SCA-P; P stands for invariant patterns) with one up to six clusters and one up to six components (comps); (B) VAFs of the Positive Affect (PA)-Cluster, the PA-Differentiated(diff)-Negative Affect (NA)Cluster, and the PA-NA-Cluster with up to six components.

clustering solution from clusterwise SCA-P using graphical representations. This approach demonstrates why we think the results of previous analyses provide a misleading picture of age differences in affect complexity. We start with visualizing age differences in NA occurrence across time, as this is where the major age group difference in variability lies. Figure 2A shows, separately for age groups and clusters, the distribution of the percentage of "0" ratings in the NA domain across 100 occasions. The large majority of individuals in the PA-Cluster have about $96 \%$ "0" ratings. That is, these individuals did not report anything but " 0 " on NA items in about 960 out of 1,000 possible ratings $(4 \%)$. This absence of NA clearly limits variability (i.e., it induces the restriction of range phenomenon). The percentage of " 0 " ratings decreases in the other clusters.
Figure $2 \mathrm{~B}$ represents the distribution of the co-occurrence index (the PA-NA correlation) from conventional analyses, grouped by age and cluster. The large majority of correlations in the PA-Cluster are closer to zero (average correlation $=-.09)$ than are the correlations in the other two clusters (average correlations are -.17 and -.21 , respectively). Taking the absence of NA variability in this cluster into account underscores the point that the zero-correlations are not indicative of more complexity. Instead, they seem to have emerged from low variability that also resulted in the one-component solution. In other words, if one takes the absence of variability in older adults into account, it is clear that size of the correlation is linked to a lack of variability rather than being indicative of more covariation. 
Table 4

Results From Clusterwise Simultaneous Component Analysis (Clusterwise SCA-P; P Stands for Invariant Patterns)

\begin{tabular}{|c|c|c|c|c|c|c|c|c|}
\hline & \multicolumn{2}{|c|}{ PA-Cluster } & \multicolumn{2}{|c|}{ PA-Differentiated-NA-Cluster } & \multirow[b]{2}{*}{$S D$} & \multicolumn{2}{|c|}{ PA-NA-Cluster } & \multirow[b]{2}{*}{$S D$} \\
\hline & Loadings PA & $S D$ & Loadings PA & Loadings NA_restr & & Loadings PA & Loadings NA & \\
\hline Distressed & -.008 & 0.31 & -.023 & 0.77 & 1.10 & -.020 & 0.82 & 1.20 \\
\hline Upset & -.004 & 0.26 & 0.00 & 0.77 & 0.97 & -.001 & 0.82 & 1.14 \\
\hline Guilty & -.001 & 0.15 & -.002 & 0.16 & 0.43 & -.003 & 0.60 & 0.98 \\
\hline Scared & -.001 & 0.11 & 0.00 & 0.12 & 0.35 & 0.04 & 0.66 & 0.91 \\
\hline Hostile & -.001 & 0.11 & 0.02 & 0.32 & 0.51 & 0.00 & 0.51 & 0.89 \\
\hline Irritable & -.003 & 0.29 & 0.00 & 0.72 & 0.96 & -.007 & 0.62 & 1.00 \\
\hline Ashamed & -.002 & 0.15 & -.001 & 0.11 & 0.37 & 0.00 & 0.62 & 0.99 \\
\hline Nervous & 0.00 & 0.32 & 0.17 & 0.60 & 0.93 & 0.15 & 0.73 & 1.04 \\
\hline Jittery & -.001 & 0.32 & 0.18 & 0.71 & 1.02 & 0.15 & 0.75 & 1.09 \\
\hline Afraid & -.001 & 0.13 & 0.00 & 0.16 & 0.40 & 0.03 & 0.70 & 0.94 \\
\hline Enthusiastic & 0.50 & 0.76 & 0.60 & -.012 & 0.95 & 0.66 & -.009 & 1.05 \\
\hline Excited & 0.47 & 0.78 & 0.64 & 0.01 & 0.97 & 0.66 & 0.08 & 1.00 \\
\hline Strong & 0.45 & 0.76 & 0.58 & -.006 & 0.87 & 0.54 & -.017 & 0.95 \\
\hline Interested & 0.46 & 0.69 & 0.50 & -.001 & 0.79 & 0.60 & -.001 & 0.90 \\
\hline Proud & 0.16 & 0.57 & 0.51 & -.009 & 0.95 & 0.54 & -.008 & 1.03 \\
\hline Alert & 0.45 & 0.71 & 0.62 & 0.02 & 0.90 & 0.62 & 0.02 & 0.98 \\
\hline Inspired & 0.61 & 0.91 & 0.59 & 0.08 & 0.94 & 0.71 & 0.14 & 1.05 \\
\hline Determined & 0.50 & 0.78 & 0.62 & 0.04 & 0.93 & 0.60 & 0.01 & 0.98 \\
\hline Attentive & 0.44 & 0.66 & 0.52 & -.002 & 0.81 & 0.59 & -.002 & 0.89 \\
\hline Active & 0.47 & 0.71 & 0.63 & 0.04 & 0.85 & 0.66 & 0.00 & 0.93 \\
\hline Component correlation & & & & -.19 & & & & \\
\hline
\end{tabular}

Note. $\quad$ PA = positive affect; NA = negative affect; restr = restricted. Numbers in boldface indicate meaningful coefficients; the SDs are cluster specific

Figure $2 \mathrm{C}$ represents the distributions of the number of components from conventional analyses based on correlation matrices, grouped by age and cluster. The number of components is diverse in all clusters. This demonstrates that the number of components that is extracted is independent from affect variability. It is striking, for example, that there is a considerable number of individuals with a large number of components in the PA-Cluster-despite the fact that NA experiences are almost absent in this cluster. That is,

Table 5

Overview on Age-Group Specific Cluster Belongings

\begin{tabular}{|c|c|c|c|c|}
\hline Cluster & Group & Components & $\begin{array}{l}\text { Average } \\
\text { variances }\end{array}$ & $\begin{array}{c}\text { Average } \\
\text { component } \\
\text { correlations }\end{array}$ \\
\hline \multicolumn{5}{|c|}{ Total sample } \\
\hline \multirow[t]{2}{*}{ PA-Cluster } & 15 younger & PA & 2.22 & \\
\hline & 57 older & PA & 0.70 & \\
\hline \multirow[t]{4}{*}{ PA-Differentiated-NA-Cluster } & 43 younger & PA & 1.39 & -.18 \\
\hline & & NA_differentiated & 1.38 & \\
\hline & 36 older & PA & 0.57 & -.19 \\
\hline & & NA_differentiated & 0.58 & \\
\hline \multirow[t]{4}{*}{ PA-NA-Cluster } & 43 younger & $\mathrm{PA}^{-}$ & 1.11 & -.22 \\
\hline & & NA & 1.10 & \\
\hline & 10 older & PA & 0.67 & -.25 \\
\hline & & NA & 0.61 & \\
\hline \multicolumn{5}{|c|}{ Matched sample } \\
\hline \multirow[t]{4}{*}{ Matched-Cluster-1 } & 11 younger & PA & 0.72 & \\
\hline & & NA_differentiated_1 & 0.90 & -.003 \\
\hline & 14 older & PA & 1.25 & \\
\hline & & NA_differentiated_1 & 1.10 & -.26 \\
\hline \multirow[t]{4}{*}{ Matched-Cluster-2 } & 16 younger & PA & 1.17 & \\
\hline & & NA_differentiated_2 & 1.06 & -.17 \\
\hline & 13 older & PA & 0.82 & \\
\hline & & NA_differentiated_2 & 0.84 & -.33 \\
\hline
\end{tabular}

Note. $\mathrm{PA}=$ positive affect; $\mathrm{NA}=$ negative affect. The age group difference in the component correlation of the PA-Differentiated-NA-Cluster and the PA-NA-Clusters is not significant; the component correlations are more negative in older than younger adults of Matched-Cluster-1; they do not differ between age groups in Matched-Cluster-2. 


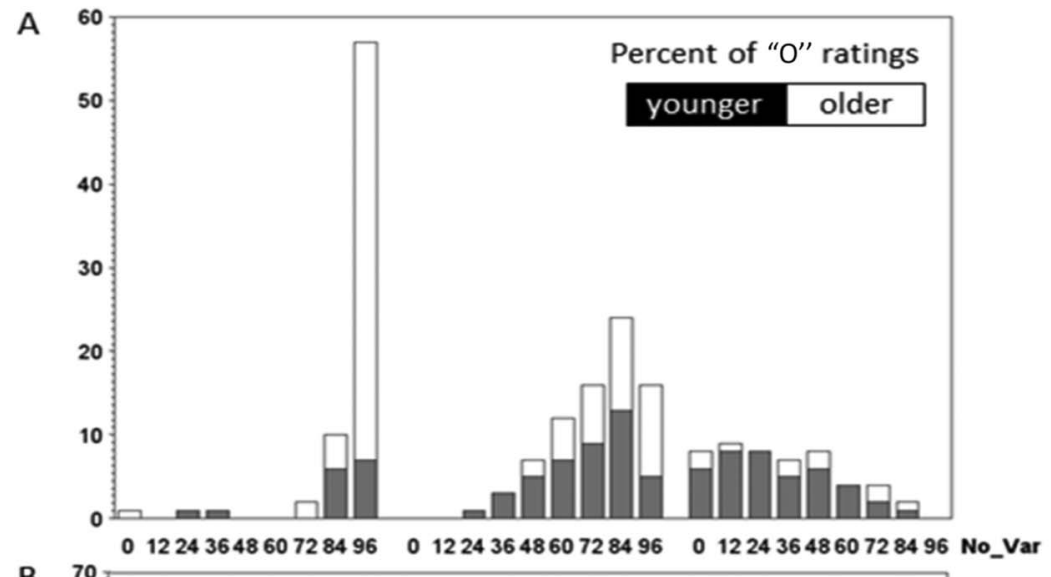

B

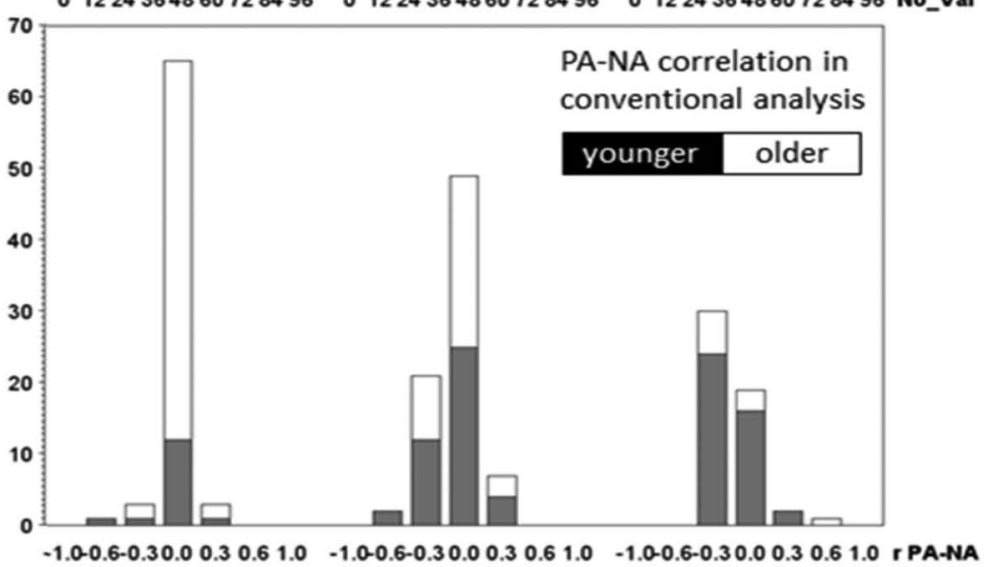

C

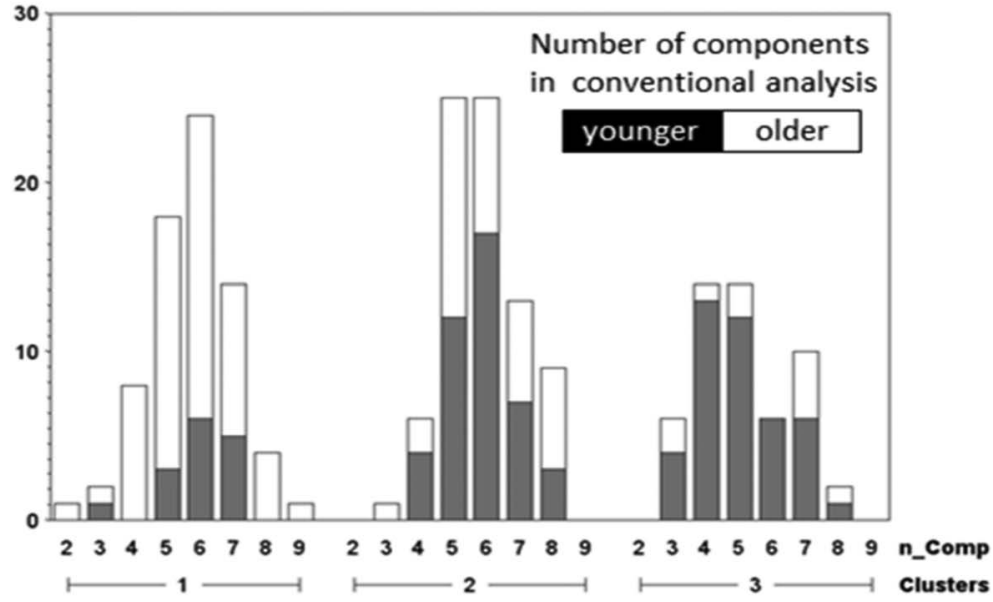

Figure 2. Distributions of (A) the percentage of "0" ratings (No_var), (B) the co-occurrence index ( $r$ PA-NA), and $(\mathrm{C})$ the differentiation index (n_Comp) in the three clusters, the Positive Affect (PA)-Cluster (Cluster 1), the PA-Differentiated Negative Affect (NA)-Cluster (Cluster 2), and the PA-NA-Cluster (Cluster 3). Please note that the distributions are displayed separately for the two age groups: They are stacked displays with older adults being represented on top of younger adults.

conventional analyses identified components that seem to be of arbitrary relevance in the ups and downs of everyday affective experiences. The differentiation index seems to provide a biased picture on affective experiences in daily life, as the importance of different aspects of emotional functioning in relation to each other are obscured.
Aim 3. Clusterwise SCA-P with younger and older adults matched on variability. Clusterwise SCA-P was repeated with subsamples of younger and older adults that were matched on affect variability using propensity score matching. We explored age differences in those uncommonly stable younger and variable older adults $(N=54)$. Tables 5 and 6 present the solution 
Table 6

Loading Matrices for the Clusters of the Matched Sample

\begin{tabular}{lccccc}
\hline & \multicolumn{2}{c}{ Matched-Cluster-1 } & & \multicolumn{2}{c}{ Matched-Cluster- 2} \\
\cline { 2 - 3 } \cline { 5 - 6 } \cline { 5 - 6 } Variable & \multicolumn{2}{c}{ Loadings } & & \multicolumn{2}{c}{ Loadings } \\
\cline { 2 - 3 } \cline { 5 - 6 } Distressed & PA & NA_restr & & PA & NA \\
Upset & -.014 & $\mathbf{0 . 7 2}$ & & -.019 & $\mathbf{0 . 6 9}$ \\
Guilty & -.005 & $\mathbf{0 . 4 1}$ & & -.005 & $\mathbf{0 . 7 7}$ \\
Scared & -.01 & 0.02 & & -.007 & $\mathbf{0 . 3 5}$ \\
Hostile & 0.002 & 0.08 & & -.005 & 0.29 \\
Irritable & -.005 & 0.16 & & -.002 & 0.25 \\
Ashamed & 0.00 & 0.58 & & -.002 & $\mathbf{0 . 5 7}$ \\
Nervous & -.002 & $\mathbf{0 . 6 0}$ & & 0.00 & $\mathbf{0 . 3 3}$ \\
Jittery & -.003 & $\mathbf{0 . 7 1}$ & & -.004 & $\mathbf{0 . 4 6}$ \\
Afraid & -.002 & 0.12 & & -.003 & $\mathbf{0 . 3 0}$ \\
Enthusiastic & $\mathbf{0 . 5 4}$ & -.006 & & $\mathbf{0 . 5 2}$ & -.009 \\
Excited & $\mathbf{0 . 6 0}$ & -.003 & & $\mathbf{0 . 5 5}$ & -.004 \\
Strong & $\mathbf{0 . 5 5}$ & -.008 & & $\mathbf{0 . 5 7}$ & -.021 \\
Interested & $\mathbf{0 . 5 6}$ & -.003 & & $\mathbf{0 . 4 1}$ & -.007 \\
Proud & 0.16 & 0.02 & & $\mathbf{0 . 5 2}$ & -.014 \\
Alert & $\mathbf{0 . 6 7}$ & -.010 & & $\mathbf{0 . 4 7}$ & -.011 \\
Inspired & $\mathbf{0 . 6 8}$ & -.003 & & $\mathbf{0 . 6 1}$ & 0.05 \\
Determined & $\mathbf{0 . 6 3}$ & -.001 & & $\mathbf{0 . 5 7}$ & -.005 \\
Attentive & $\mathbf{0 . 6 0}$ & -.006 & $\mathbf{0 . 4 3}$ & -.010 \\
Active & $\mathbf{0 . 7 0}$ & -.007 & $\mathbf{0 . 5 1}$ & -.010 \\
\hline & & &
\end{tabular}

Note. $\mathrm{PA}=$ positive affect; $\mathrm{NA}=$ negative affect; restr $=$ restricted. Numbers in boldface indicate meaningful coefficients.

of clusterwise SCA-P. Two clusters emerged, which we refer to as Matched-Cluster-1 and Matched-Cluster-2. The loading pattern of Matched-Cluster-1 revealed a PA and NA component that was restricted in scope. Matched-Cluster-2 differs from Matched-Cluster-1 in that the PA and NA components are broader in scope. A $\chi^{2}$ test revealed that the membership of individuals in the specific clusters is not age-group specific, $\chi^{2}=0.67, p=.41$. That is, younger and older adults with comparable affect variability do not differ in loading patterns. The component correlations are more negative in older than younger adults in Matched-Cluster-1, $F(1,23)=7.25, p=.01$, but they do not differ in Matched-Cluster-2, $F(1,27)=2.87$, $p=.10$. Thus, older and younger adults whose everyday life affective experiences are similarly variable are largely similar in affect complexity, with some indication that there is less complexity in older adults.

Aim 4. Emotional complexity and well-being. Finally, we tested whether the clusters that emerged from clusterwise SCA-P differed on indicators of well-being (depressive symptoms, trait NA and PA, and happiness). Mean levels of wellbeing per cluster and age group are presented in Figure 3. Four ANOVAs (factor: cluster, number of levels $=$ three) revealed that the highest levels of well-being occurred in the least complex cluster (the PA-cluster), followed by the PADifferentiated-NA-Cluster. In particular, the main effects for cluster were significant in depressive symptoms, $F(2,202)=$ $15.79, p<.001, \eta^{2}=0.14$, in trait NA, $F(2,202)=25.41, p<$ $.0001, \eta^{2}=0.20$, and in happiness, $F(2,202)=17.96, p<$ $.001, \eta^{2}=0.15$. No group differences emerged in in trait PA, $F(2,202)=0.16, p=.16, \eta^{2}=0.02$. Pairwise comparisons using Tukey tests revealed significant differences in depression and trait NA between all three clusters, but no significant differences in trait PA between clusters. For trait happiness, the pairwise comparisons revealed a difference between the PAcluster and the other two clusters, but not between the PADifferentiated-NA-Cluster and the PA-NA-Cluster. In sum, the highest levels of well-being were found in individuals with a positively biased affect structure (individuals in the PACluster). Moderate levels were found in the PA-DifferentiatedNA-Cluster. The lowest levels of well-being were found in the PA-NA-Cluster in which individuals commonly experience PA and NA but in an undifferentiated manner.
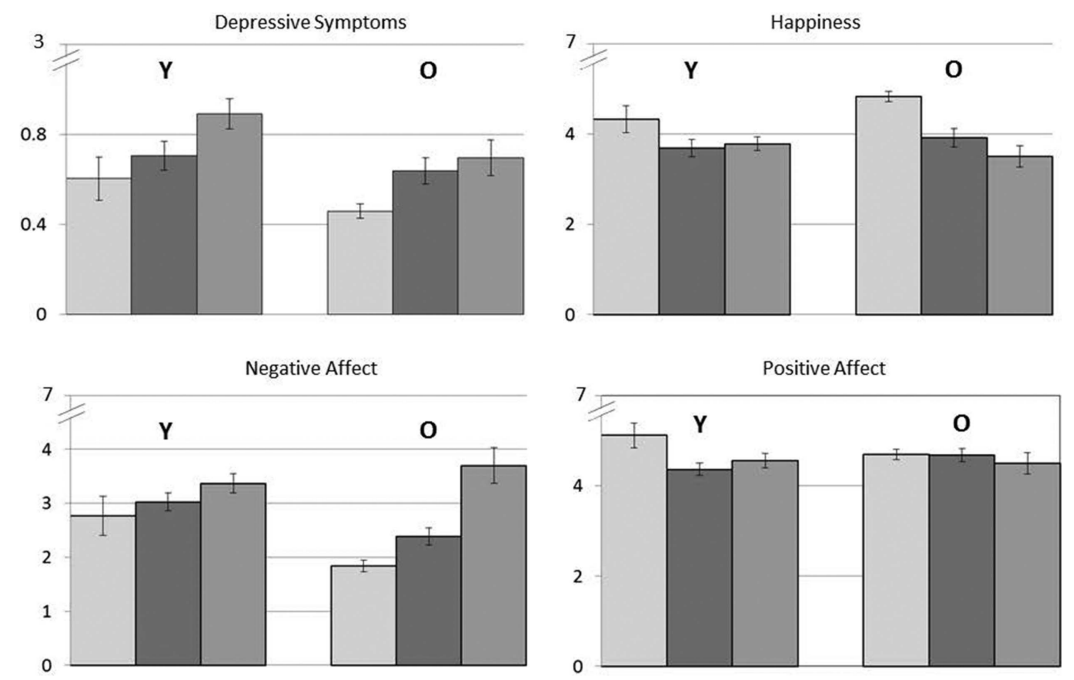

Figure 3. Mean levels of indicators of well-being, separately for age groups ( $\mathrm{Y}$ and $\mathrm{O}$ stands for younger and older adults) and clusters. 


\section{Follow-Up Analysis}

The results from clusterwise SCA-P presented in Figure 2A are related to the relative absence of a number of negative states. One could thus wonder whether the information on individual differences in mean levels is sufficient to identify clusters that differ in affective experiences across time. That is, to what degree can the clusters be recapped through the analysis of individual differences in the mean levels of affective states? To examine this, we ran K-means clustering on the person-specific item means. A twocluster solution emerged, in which younger and older adults fell mainly into two separate clusters, and in which younger adults had higher levels of NA and lower levels of PA than older adults. These results clearly shed less light on emotional complexity than the clusterwise SCA-P analyses on the individuals' time series. Hence, the analysis of covariance structures cannot be replaced by an analysis of mean levels.

\section{Discussion}

Some previous research has claimed that the affective lives of older adults are more complex than their younger counterparts. In contrast to this assertion, we found that if reduced variability in older adults' affective lives is taken into account, older adults' everyday affective experiences are less complex than those of younger adults. We drew our main conclusions from clusterwise SCA-P, a method that was developed to group multiple entities with similar structural characteristics (the pattern of covariation in time series data in this study) into mutually exclusive clusters. The majority of older adults were grouped into a cluster without a NA component, indicating that among these individuals, NA is not relevant in describing the ups and downs of daily affect. This suggests that these older adults usually did not experience positive and NA simultaneously (i.e., no co-occurrence), and their affective lives were not differentiated in the sense of a high-dimensional affective structure. More complex affective responding, including PA and NA and a relatively differentiated pattern, was found in about one third of the older adults. In contrast, most younger adults belonged to clusters with a positive and a more or less differentiated NA component (the PA-Differentiated-NA-Cluster and the PA-NACluster). These results are clearly tied to affect variability-it is the amount of variability in NA in daily life that is driving these results and, relatedly, the relative absence of negative states in many older adults to begin with. Those facets of affect that were comparatively stable across study time were of negligible relevance for the patterns revealed by clusterwise SCA-P (e.g., NA items in the PA-Cluster). Adjusting for age differences in affect variability using propensity score matching revealed largely comparable structures of affect complexity across the two age groups.

In addition, the results underscore the relevance of affect complexity for well-being. They go beyond prior research in demonstrating that not only differentiated affective lives, but also affective lives that are positively biased are positively related to well-being. In fact, the highest levels of well-being were found in individuals without a NA component, which were mainly older adults.

\section{Affect Variability, Affect Complexity, and Well-Being}

In more than half of the older subsample and relatively fewer younger adults (56\% vs. 15\%), affective experiences in daily life were best represented by a single PA component (the PA-Cluster). In this cluster, negative experiences were not relevant for the dynamic changes of affect in daily life. This cluster also showed the highest levels of well-being. This is not surprising, given that individuals in this cluster are mainly affectively responsive in terms of activity, interest, and enthusiasm in daily life (these are the content domains that are captured with the PA scale of the PANAS; Zevon \& Tellegen, 1982). They do not experience NA disturbances, however. That is, they are emotionally quite stable in the NA domain and in addition, they have low levels of NA. Both are known to be related to high levels of adjustment (Houben, van de Noortgate, \& Kuppens 2014). Furthermore, and given the large proportion of older adults in this cluster, these findings seem to be in line with research on emotional aging that suggests a positivity bias in attention and memory (Reed, Chan, \& Mikels, 2014) and increased stability and well-being in older adults (Röcke \& Brose, 2013). One could speculate that individuals in this cluster are particularly good at avoiding negative experiences in the first place - the selection of situations in accordance with emotional goals is currently discussed as an important emotion regulation strategy for older adults' levels of well-being (Charles, Piazza, Luong, \& Almeida, 2009; Urry \& Gross, 2010).

Most of the remaining older (35\%) and relatively more younger adults $(43 \%)$ belonged to the PA-Differentiated-NA-Cluster, which we consider to be the most affectively complex. These individuals commonly experienced positive and negative states. Yet, their affect patterns were relatively differentiated in the negative domain - not all facets of NA traveled together across time. The scope of the negative component was constrained to a subset of the measured items (i.e., distressed, upset, hostile, irritable, nervous, and jittery). Finally, a relatively large amount of younger adults and some older adults (43\% vs. 10\%) belonged to the PA-NA-Cluster. This cluster also had a PA and NA component. However, the degree of differentiation in the NA component was reduced in this cluster; its scope was rather broad and not constrained as in in the PA-Differentiated-NA-Cluster. Comparing these two clusters, the individuals with the more complex structure had higher levels of well-being than those in the less complex structure (i.e., lower levels of depressive symptoms and NA). This is in line with the idea that more nuanced emotional experiences are beneficial in terms of well-being, potentially because such experiences provide the basis for adequate responding to and handling of situations (Erbas, Ceulemans, Lee Pe, Koval, \& Kuppens, 2014; Lindquist \& Barrett, 2008).

The age group specific distribution of study participants across the three clusters is noteworthy. Older adults not only had the lowest complexity, but they were mainly grouped into the cluster with the highest level of well-being. It thus seems that relatively beneficial affective experiences can take two distinct forms in older adulthood. In contrast, younger adults were generally more complex. It is important for younger adults, however, to have differentiated negative affective responses, because undifferentiated negative experiences that are broad in scope are negatively related to well-being in this age group. 


\section{Affective Experiences in Meaningful Moments}

We limit our conclusions on age differences in affect complexity to everyday affective experiences. That is, we do not make claims about the development of affect complexity more generally, and we do not contend that our findings would replicate in highly meaningful moments. In these situations, the propositions regarding affect complexity raised by SST are likely to be important. For example, when compared with younger adults, older adults are likely think more often about experiencing things for the last time, and this should come with bittersweet feelings. In addition, older adults, when faced with a threat, may try to make meaning of the threat more than younger adults (Carstensen et al., 2000), and this may serve to maintain positive emotions. Such age-related changes should indeed increase affect complexity. Yet, these propositions seem to apply to particularly meaningful situations and to moments when older adults are faced with threats-which are not the moments that are prototypical for older adults' comparatively routinized and less stressful daily lives (Bouisson \& Swendsen, 2003; Brose et al., 2013).

Experimental research also supports the view that affect complexity may occur in meaningful situations and when there is an awareness of things coming to an end. For example, ErsnerHershfield and colleagues (2008) had participants think about "last times," and when the participants were asked to imagine these meaningful situations, their mixed emotions increased. Experimental research also suggests that personally relevant emotional stimuli can, in principle, elicit even stronger emotional reactions in older than younger adults (e.g., Kunzmann \& Grühn, 2005), and these increased reactions might come with more complexity. To support these propositions with ambulatory assessment, future research could consider a shift from experience sampling to an event sampling paradigms. Such a paradigm would reveal age differences in affect complexity in comparably meaningful situations. Matching younger and older adults on variability, as we did in this study is an important first step in this direction. Our method revealed that age differences in complexity largely dissipated once variability was taken into account. Yet, adjusting for variability does not guarantee comparable relevance of emotional situations, and it also creates age groups of uncommonly stable younger and uncommonly variable older adults. Thus, it cannot serve as a substitute for event sampling.

\section{Limitations and Future Directions}

One of the obvious limitations of this study is that it was a laboratory study. Filling out questionnaires in the laboratory may have reduced affect variability, and this reduction may have even occurred differentially across age groups. We addressed this issue by assessing affect at the beginning of the sessions to increase its relation to daily experiences. Other articles from the COGITO study have revealed systematic covariation of affect with other self-reported daily experiences in both age groups (social support, physical symptoms, and daily stress; Brose, Schmiedek, Lövdén, \& Lindenberger, 2011; Wolff, Schmiedek, Brose, \& Lindenberger, 2013). Therefore, it is safe to say that affect, even if measured in the lab, is a reasonably accurate reflection of affect in daily life. In addition, experience sampling studies that were ecologically more valid also revealed the relative absence of NA in older adults (e.g., zero-ratings in the NA domain on about $75 \%$ of the measurement occasions; Carstensen et al., 2000; in comparison to $83 \%$ in the COGITO study). This similarity across studies increases our confidence that the measurement procedure in this study is unlikely to be a major cause of the observed low variability.

Second, this study measured affect with the PANAS and thereby sampled a restricted range of the affective circumplex (i.e., states high in arousal). The dimensionality of within-person affective experiences may be higher if affective states low in arousal such as serene or sluggish were measured. This limitation should be kept in mind when viewing the dimensionality of the clusters that were revealed by clusterwise SCA-P. In addition, given that the relative importance of low arousal affective states increases with age (Kessler \& Staudinger, 2009), the selection of items may not have fully captured older adults' everyday affective experiences. Thus, it would be beneficial if this study was replicated with a set of items that are equally representative of younger and older adults' daily emotional lives.

Third, given the fact that most of the previous research on this topic was conducted in the United States, it would also be instructive to conduct a cross-cultural study on affect complexity. Such as study would allow us to evaluate the degree to which this study's findings regarding reduced affect complexity reflect cultural differences between Germany and the United States.

Fourth, it would be intriguing to further investigate sources and covariates of affect complexity within and across age groups and clusters. Two obvious candidates for such analyses would be emotion regulation and cognitive functioning. For example, agerelated increases in situation selection might prevent the occurrence of negative emotions in the first place, and individuals in the PA-Cluster might habitually use this emotion regulation strategy. Furthermore, and in line with Labouvie-Vief et al.'s reasoning (Labouvie-Vief et al., 2010), cognitive functioning might be reduced in the PA-Cluster, and reduced complexity might be indicative of reduced cognitive integration. Investigations of both these issues would benefit from a longitudinal design and the inclusion of middle-aged adults to assess developmental change.

Finally, average affect structures across multiple individuals' time series as revealed by clusterwise SCA-P may not be representative of single individuals' structure (Molenaar, 2004). In fact, a recent work from the COGITO study revealed much heterogeneity in individuals' factor structures (Brose, Voelkle, Lövdén, Lindenberger, \& Schmiedek, in press). As a consequence, idiosyncrasies in affective experiences are likely not captured by this study's approach, and this should be recognized when interpreting these results.

\section{Conclusion}

In this study, we demonstrated that there was reduced affect complexity in older compared with younger adults, a finding that differs from most previous studies. Reduced complexity was reflected by a positively biased structure in this study, in the sense that the structure was reduced to a PA affect component. Also in contrast with previous studies, this study approached structural complexity while taking considerable adult age differences in affect variability into account-older adults' affect varied less across time, particularly in the NA domain. It is our view that a conjoint consideration of co-occurrence and variability, as conducted in this study, affords a more accurate picture of the emo- 
tional lives of younger and older adults and also provides an appropriate reflection of the major age differences. It is interesting that those individuals with lowest affect complexity had the highest levels of well-being. Because low affective complexity occurred mainly in older adults, we conclude that older adults are able to constrain affective responding to daily matters to the PA domain, while being able to keep NA at low levels and stable across time.

\section{References}

Barrett, L. F., Gross, J., Christensen, T. C., \& Benvenuto, M. (2001). Knowing what you're feeling and knowing what to do about it: Mapping the relation between emotion differentiation and emotion regulation. Cognition and Emotion, 15, 713-724. http://dx.doi.org/10.1080/ 02699930143000239

Bouisson, J., \& Swendsen, J. (2003). Routinization and emotional wellbeing: An experience sampling investigation in an elderly French sample. The Journals of Gerontology Series B, Psychological Sciences and Social Sciences, 58, P280-P282. http://dx.doi.org/10.1093/geronb/58.5 .P280

Brose, A., Scheibe, S., \& Schmiedek, F. (2013). Life contexts make a difference: Emotional stability in younger and older adults. Psychology and Aging, 28, 148-159. http://dx.doi.org/10.1037/a0030047

Brose, A., Schmiedek, F., Lövdén, M., \& Lindenberger, U. (2011). Normal aging dampens the link between intrusive thoughts and negative affect in reaction to daily stressors. Psychology and Aging, 26, 488-502. http:// dx.doi.org/10.1037/a0022287

Brose, A., Voelkle, M. C., Lövdén, M., Lindenberger, U., \& Schmiedek, F. (in press). Differences in the between- and the within-person structures of affect are a matter of degree. European Journal of Personality.

Carstensen, L. L., Pasupathi, M., Mayr, U., \& Nesselroade, J. R. (2000). Emotional experience in everyday life across the adult life span. Journal of Personality and Social Psychology, 79, 644-655. http://dx.doi.org/ 10.1037/0022-3514.79.4.644

Carstensen, L. L., Turan, B., Scheibe, S., Ram, N., Ersner-Hershfield, H., Samanez-Larkin, G. R., . . . Nesselroade, J. R. (2011). Emotional experience improves with age: Evidence based on over 10 years of experience sampling. Psychology and Aging, 26, 21-33. http://dx.doi .org/10.1037/a0021285

Charles, S. T. (2005). Viewing injustice: Greater emotion heterogeneity with age. Psychology and Aging, 20, 159-164. http://dx.doi.org/ 10.1037/0882-7974.20.1.159

Charles, S. T., Piazza, J. R., Luong, G., \& Almeida, D. M. (2009). Now you see it, now you don't: Age differences in affective reactivity to social tensions. Psychology and Aging, 24, 645-653. http://dx.doi.org/ 10.1037/a0016673

De Roover, K., Ceulemans, E., \& Timmerman, M. E. (2012). How to perform multiblock component analysis in practice. Behavior Research Methods, 44, 41-56. http://dx.doi.org/10.3758/s13428-011-0129-1

De Roover, K., Ceulemans, E., Timmerman, M. E., \& Onghena, P. (2013). A clusterwise simultaneous component method for capturing withincluster differences in component variances and correlations. British Journal of Mathematical and Statistical Psychology, 66, 81-102. http:// dx.doi.org/10.1111/j.2044-8317.2012.02040.x

De Roover, K., Ceulemans, E., Timmerman, M. E., Vansteelandt, K., Stouten, J., \& Onghena, P. (2012). Clusterwise simultaneous component analysis for analyzing structural differences in multivariate multiblock data. Psychological Methods, 17, 100-119. http://dx.doi.org/10.1037/ a0025385

Erbas, Y., Ceulemans, E., Lee Pe, M., Koval, P., \& Kuppens, P. (2014). Negative emotion differentiation: Its personality and well-being correlates and a comparison of different assessment methods. Advance online publication. Cognition and Emotion, 28, 1196-1213. http://dx.doi .org/10.1080/02699931.2013.875890

Ersner-Hershfield, H., Mikels, J. A., Sullivan, S. J., \& Carstensen, L. L. (2008). Poignancy: Mixed emotional experience in the face of meaningful endings. Journal of Personality and Social Psychology, 94, 158-167. http://dx.doi.org/10.1037/0022-3514.94.1.158

Grühn, D., Lumley, M. A., Diehl, M., \& Labouvie-Vief, G. (2013). Time-based indicators of emotional complexity: Interrelations and correlates. Emotion, 13, 226-237. http://dx.doi.org/10.1037/a0030363

Hautzinger, M. (1988). Die CES-D Skala. Ein Depressionsmeßinstrument für Untersuchungen in der Allgemeinbevölkerung [The CES-D Scale: A measure of depressive symptoms for studying normal populations]. Diagnostica, 31, 167-173.

Hay, E. L., \& Diehl, M. (2011). Emotion complexity and emotion regulation across adulthood. European Journal of Ageing, 8, 157-168. http:/ dx.doi.org/10.1007/s10433-011-0191-7

Ho, D. E., Imai, K., King, G., \& Stuart, E. A. (2007). Matching as nonparametric preprocessing for reducing model dependence in parametric causal inference. Political Analysis, 15, 199-236. http://dx.doi .org/10.1093/pan/mpl013

Houben, M., van de Noortgate, W., \& Kuppens, P. (2014). The relation between patterns of emotional change and psychological well-being: A meta-analysis. Manuscript submitted for publication.

Kessler, E.-M., \& Staudinger, U. M. (2009). Affective experience in adulthood and old age: The role of affective arousal and perceived affect regulation. Psychology and Aging, 24, 349-362. http://dx.doi.org/ 10.1037/a0015352

Kiers, H. A. L., \& Tenberge, J. M. F. (1994). The Harris-Kaiser independent cluster rotation as a method for rotation to simple component weights. Psychometrika, 59, 81-90. http://dx.doi.org/10.1007/ BF02294267

Kunzmann, U., \& Grühn, D. (2005). Age differences in emotional reactivity: The sample case of sadness. Psychology and Aging, 20, 47-59. http://dx.doi.org/10.1037/0882-7974.20.1.47

Labouvie-Vief, G. (2003). Dynamic integration: Affect, cognition, and the self in adulthood. Current Directions in Psychological Science, 12, 201-206. http://dx.doi.org/10.1046/j.0963-7214.2003.01262.x

Labouvie-Vief, G., Grühn, D., \& Studer, J. (2010). Dynamic integration of emotion and cognition: Equilibrium regulation in development and aging. In R. M. Lerner, M. E. Lamb, \& A. M. Freund (Eds.), The handbook of life-span development (Vol. 2, pp. 79-115). Hoboken, NJ: Wiley. http://dx.doi.org/10.1002/9780470880166.hlsd002004

Lindquist, K., \& Barrett, L. F. (2008). Emotional complexity. In M. Lewis, J. M. Haviland-Jones, \& L. F. Barrett (Eds.), The handbook of emotion (3rd ed., pp. 513-530). New York, NY: Guilford Press.

Luong, G., Charles, S. T., \& Fingerman, K. L. (2011). Better with age: Social relationships across adulthood. Journal of Social and Personal Relationships, 28, 9-23. http://dx.doi.org/10.1177/0265407510391362

Magai, C., Consedine, N. S., Krivoshekova, Y. S., Kudadjie-Gyamfi, E., \& McPherson, R. (2006). Emotion experience and expression across the adult life span: Insights from a multimodal assessment study. Psychology and Aging, 21, 303-317.

Molenaar, P. C. M. (2004). A manifesto on psychology as idiographic science: Bringing the person back into scientific psychology, this time forever. Measurement, 2, 201-218.

Ong, A. D., \& Bergeman, C. S. (2004). The complexity of emotions in later life. The Journals of Gerontology Series B, Psychological Sciences and Social Sciences, 59, P117-P122. http://dx.doi.org/10.1093/geronb/59.3 .P117

Ready, R. E., Carvalho, J. O., \& Weinberger, M. I. (2008). Emotional complexity in younger, midlife, and older adults. Psychology and Aging, 23, 928-933. http://dx.doi.org/10.1037/a0014003

Reed, A. E., Chan, L., \& Mikels, J. A. (2014). Meta-analysis of the age-related positivity effect: Age differences in preferences for positive 
over negative information. Psychology and Aging, 29, 1-15. http://dx .doi.org/10.1037/a0035194

Riediger, M., \& Rauers, A. (2014). Do everyday affective experiences differ throughout adulthood? A review of ambulatory-assessment evidence. In P. Verhaeghen \& C. Hertzog (Eds.), The Oxford handbook of emotion, social cognition, and everyday problem solving during adulthood (pp. 61-82). New York, NY: Oxford University Press.

Riediger, M., Schmiedek, F., Wagner, G. G., \& Lindenberger, U. (2009). Seeking pleasure and seeking pain: Differences in prohedonic and contra-hedonic motivation from adolescence to old age. Psychological Science, 20, 1529-1535. http://dx.doi.org/10.1111/j.1467-9280.2009 .02473.x

Röcke, C., \& Brose, A. (2013). Intraindividual variability and stability of affect and well-being. Short-term and long-term change and stabilization processes. GeroPsych, 26, 185-199.

Röcke, C., Li, S.-C., \& Smith, J. (2009). Intraindividual variability in positive and negative affect over 45 days: Do older adults fluctuate less than young adults? Psychology and Aging, 24, 863-878. http://dx.doi .org/10.1037/a0016276

Rosenkoetter, M. M., Garris, J. M., \& Engdahl, R. A. (2001). Postretirement use of time: Implications for preretirement planning and postretirement management. Activities, Adaptation \& Aging, 25, 1-18. http:// dx.doi.org/10.1300/J016v25n03_01

Schmiedek, F., Lövdén, M., \& Lindenberger, U. (2009). On the relation of mean reaction time and intraindividual reaction time variability. Psychology and Aging, 24, 841-857. http://dx.doi.org/10.1037/a0017799
Scott, S. B., Sliwinski, M. J., Mogle, J. A., \& Almeida, D. M. (2014). Age, stress, and emotional complexity: Results from two studies of daily experiences. Psychology and Aging, 29, 577-587. http://dx.doi.org/ 10.1037/a0037282

Steptoe, A., Leigh, E. S., \& Kumari, M. (2011). Positive affect and distressed affect over the day in older people. Psychology and Aging, 26, 956-965. http://dx.doi.org/10.1037/a0023303

Urry, H. L., \& Gross, J. J. (2010). Emotion regulation in older age. Current Directions in Psychological Science, 19, 352-357. http://dx.doi.org/ 10.1177/0963721410388395

Watson, D., Clark, L. A., \& Tellegen, A. (1988). Development and validation of brief measures of positive and negative affect: The PANAS scales. Journal of Personality and Social Psychology, 54, 1063-1070. http://dx.doi.org/10.1037/0022-3514.54.6.1063

Wolff, J. K., Schmiedek, F., Brose, A., \& Lindenberger, U. (2013) Physical and emotional well-being and the balance of needed and received emotional support: Age differences in a daily diary study. Social Science \& Medicine, 91, 67-75. http://dx.doi.org/10.1016/j socscimed.2013.04.033

Zevon, M. A., \& Tellegen, A. (1982). The structure of mood change: An idiographic/nomothetic analysis. Journal of Personality and Social Psychology, 43, 111-122. http://dx.doi.org/10.1037/0022-3514.43.1.111

Received June 19, 2014 Revision received November 7, 2014 Accepted November 14, 2014 